\title{
7. CASE Study: Control of bovine respiratory disease in dairy calves with tulathromycin and effect on calf health and performance from 0 to 4 months of age
}

\author{
T. M. Hill, ${ }^{1}$ J. D. Quigley, F. X. Suarez-Mena, PAS, T. S. Dennis, and R. L. Schlotterbeck \\ Nurture Research Center, Provimi, Brookville, OH 45309
}

\begin{abstract}
In phase 1,96 male Holstein calves at risk for bovine respiratory disease initially 2 to $4 \mathrm{~d}$ of age from a single dairy farm were transported $3.5 \mathrm{~h}$ to southwest Ohio. Calves were randomly assigned to receive a s.c. injection of Draxxin (2.5 mg of tulathromycin $/ \mathrm{kg}$ of BW; Zoetis, Florham Park, NJ; TUL) at arrival $(\mathrm{d}-1)$ and again at weaning (d 42) or receive no injections (CON). Milk replacer was fed at $0.66 \mathrm{~kg}$ of DM daily for $39 \mathrm{~d}$ and then $0.33 \mathrm{~kg}$ of DM daily for $3 \mathrm{~d}$. A high-grain, textured starter and water were fed free choice for the first 56 -d phase. In phase 2 , the same calves from phase 1 were grouped by CON and TUL and moved to group pens (4 pens per treatment; 4 calves per pen) for the next $56 \mathrm{~d}$. The same starter from phase 1 was blended with $5 \%$ chopped grass hay and fed free choice. In phase 1, postweaning starter intake and $\mathrm{BW}$ gain, overall $\mathrm{BW}$ gain, and final $\mathrm{BW}$ were greater for TUL than CON. Medical treatments did not differ. During phase 2, DMI (\% of BW) was greater for CON than TUL. Calf BW gain, final BW, feed efficiency, and hip width change were greater for TUL than CON. Over the $112 \mathrm{~d}$ of both phases, TUL calves gained $9.0 \mathrm{~kg}$ (9\%) more BW (106.4 vs. $97.4 \mathrm{~kg}$ ) and $0.8 \mathrm{~cm}(8 \%)$ more hip width (10 vs. $9.2 \mathrm{~cm})$ than CON calves, but TUL did not improve calf health.
\end{abstract}

Key words: growth, antibiotics, pneumonia

\section{INTRODUCTION}

Approximately $10 \%$ of dairy calves die, and calf morbidity is a significant issue (USDA-APHIS, 2009). Although the primary reason for morbidity and mortality in the preweaned dairy calf is typically enteric, bovine respiratory disease (BRD) is of significant concern in calves over 1 mo of age (Svensson et al., 2003) and is the primary cause of mortality after weaning, averaging $1.8 \%$ (USDAAPHIS, 2009).

With BRD being a primary cause of calf death, metaphylactic antibiotic treatments of weaned beef and dairy

\footnotetext{
${ }^{1}$ Corresponding author: mhill@provimi-na.com
}

calves are implemented on many farms (USDA-APHIS, 1999). Draxxin (100 mg/mL tulathromycin; Zoetis, Florham Park, NJ) is approved for control of BRD in beef cattle, nonlactating dairy cattle (including dairy calves), and veal calves at high risk of developing BRD associated with Mannheimia haemolytica, Pasteurella multocida, Histophilus somni, and Mycoplasma bovis. Although government agencies encourage less use of antibiotics in livestock (Weese et al., 2015), the metaphylactic use of tulathromycin in commingled dairy calves has been reported to lower the incidence of diarrhea, otitis media, and BRD and improve growth (Stanton et al., 2010, 2012, 2013) and suggested to possibly reduce antibiotic resistance (Weese, 2006). In calves over 2 mo of age and metaphylactically treated with TUL at approximately $3 \mathrm{~d}$ of age, TUL increased ADG and reduced the incidence of diarrhea and otitis media (Stanton et al., 2013). In calves metaphylactically treated with TUL versus oxytetracycline at approximately 2 mo of age, ADG and withers height change were increased to approximately 3.2 mo of age in calves that had not been treated for disease, and the incidence of respiratory infection was reduced (Stanton et al., 2010, 2012). Other peer-reviewed research with TUL in young dairy calves was not found.

Use of TUL to reduce risk of morbidity and mortality in dairy calves has been observed by Stanton et al. (2010, 2012, 2013); therefore, our objective was to test the metaphylactic use of TUL in preweaned dairy calves and evaluate the carryover effects after weaning. We implemented this study during a period of approximately 4 mo of treating approximately $20 \%$ of our calves for BRD, an untypically high rate for our research unit.

\section{MATERIALS AND METHODS}

Calves were cared for by acceptable practices as described in the Guide for the Care and Use of Agricultural Animals in Agricultural Research and Teaching (FASS, 2010). In phase 1, 2 groups of 48 male Holstein calves (96 total) initially 2 to $4 \mathrm{~d}$ of age from a single dairy farm were transported $3.5 \mathrm{~h}$ to the Nurture Research Center in southwest Ohio. The second group arrived $35 \mathrm{~d}$ after the first group. Upon arrival, calves were randomly assigned to receive a s.c. injection of Draxxin (2.5 mg of tulathromycin $/ \mathrm{kg}$ of 
BW; TUL) at arrival (d -1) and again at weaning (d 42) or receive no injections $(\mathbf{C O N})$. Calves were housed in 1.2 $\mathrm{m} \times 2.4 \mathrm{~m}$ individual pens with a coarse-rock, tile-drained floor bedded with straw in a curtain-sided, naturally ventilated barn with no added heat for 56 d. Milk replacer (MR) was fed at $0.66 \mathrm{~kg}$ of DM daily for $39 \mathrm{~d}$ and then $0.33 \mathrm{~kg}$ of DM daily for $3 \mathrm{~d}$. The MR was manufactured with whey, whey protein concentrate, and animal fat $(25 \%$ CP, $18 \%$ fat; Table 1), reconstituted to $14 \%$ solids with warm water, and fed at 0630 and $1400 \mathrm{~h}$ daily. A highgrain, textured starter (Table 1; fed at approximately 1300 h) and water (fed at approximately $0800 \mathrm{~h}$ ) were fed free choice for the $56 \mathrm{~d}$ of phase 1 . Every other bag of MR and starter was sampled and composited for nutrient analysis. Management practices including vaccinations and medical treatments during the trial were based on the recommendations of the herd veterinarian.

The day after arrival at approximately noon approximately $5.5 \mathrm{~h}$ after feeding MR, the calves were weighed (d 0, initial BW). At this time, blood was sampled intravenously, serum was separated by centrifugation at 3,000 $\times g\left(\right.$ VWR, Batavia, IL) at $20^{\circ} \mathrm{C}$ for $15 \mathrm{~min}$, and serum protein concentration was estimated using an optical refractometer (ATAGO USA Inc., Bellevue, WA). Calves were weighed initially and weekly thereafter at approximately noon. Body condition score (1 being thin and 5 being obese, modified from Wildman et al., 1982) and hip widths using a caliper were measured initially and every 2 wk thereafter. Phase 1 was conducted in consecutive months of October 2014 to January 2015. The average temperature in the nursery was $6^{\circ} \mathrm{C}$ with a range from -8 to $27^{\circ} \mathrm{C}$. The average relative humidity was $74 \%$ with a range from 13 to $100 \%$.

Feces were scored daily using a 1-to-5 scale with 1 being normal and 5 being watery (modified from Kertz and Chester-Jones, 2004). Calves with fecal scores of 3 or greater (considered abnormal fecal scores) received oral electrolytes that were not counted as medical treatments. During the first $28 \mathrm{~d}$, the first abnormal feces (fecal score of 3 or greater) per calf was sampled and mixed. An aliquot was tested for Cryptosporidium, Rotavirus, Coronavirus, or K99 Escherichia coli using lateral immunochromatography strips (Biox Diagnostics, Jemelle, Belgium). Antibiotic medical treatments were recorded daily. Bovine respiratory disease was defined as one or more of the following symptoms: coughing, nasal discharges, labored breathing, and rectal temperatures $>39.4^{\circ} \mathrm{C}$. Baytril 100 (Bayer Healthcare, Shawnee Mission, KS; 5 mL s.c.) was administered to calves with BRD. Banamine (Merck, Madison, NJ; $1.5 \mathrm{~mL}$ i.v.) was administered for lethargy. Navel infections were treated with $5 \mathrm{~mL}$ of penicillin $\mathrm{G}$ procaine i.m. (300,000 units/mL; Agri Laboratories LTD, St. Joseph, MO) daily for $7 \mathrm{~d}$. On d 28, 42, and 56, an experienced technician auscultated lungs of calves (right, anterior side of calves) to assist in identification of respiratory disease.
Calves received an intranasal respiratory disease vaccine (TSV-2, Zoetis, Parsippany, NJ) and s.c. injections of vitamins A, D, E (Vital E - A + D, Merck Animal Health) and Se (MU-SE, Merck Animal Health) upon arrival. Calves received an injection of Bovashield Gold 5 (Zoetis) at d 7 and again at d 28. Calves were surgically castrated and dehorned at $36 \mathrm{~d}$ of age.

In phase 2 , the same calves from phase 1 were grouped by CON and TUL and moved to group pens (12 pens per treatment with 4 calves per pen) for the next $56 \mathrm{~d}$. The pens had $6.5 \mathrm{~m}^{2}$ of outside pen space and $1.35 \mathrm{~m}^{2}$ of inside pen space per calf. Inside pen space was bedded with straw, and there was no added heat. The same starter fed in phase 1 was blended with $5 \%$ chopped grass hay (Table 1). Starter-forage mix and water were fed free choice. Every other bag of starter and every bale of hay was sampled and composited for nutrient analysis. Initially and at 84 and $112 \mathrm{~d}$, calves were weighed and scored for body condition and hip widths were measured. The trial was conducted in consecutive months of December to March immediately following phase 1 for each group of calves. Average temperature in phase 2 was $-2^{\circ} \mathrm{C}$ with a range from -22 to $15^{\circ} \mathrm{C}$. Average relative humidity was $73 \%$ with a range from 38 to $100 \%$.

Composites of feeds and refused feed were analyzed (AOAC International, 2000) for DM (oven method 930.15), ash (oven method 942.05), CP (Kjeldahl method 988.05), fat (alkaline treatment with Roese-Gottlieb method 932.06 for MR; diethyl ether extraction method 2003.05 for starters and hay), NDF with ash by the procedure of Van Soest et al. (1991) without sodium sulfite or $\alpha$-amylase, ADF with ash (Robertson and Van Soest, 1981), starch ( $\alpha$-amylase method; Hall, 2009), and sugar

Table 1. Analyzed nutrient composition of feeds

\begin{tabular}{lccc} 
Feed & Milk replacer $^{1}$ & Starter $^{2}$ & Grass hay $^{\text {(n) }}$ \\
\hline DM, \% as fed & 93.4 & 87.7 & 87.6 \\
DM basis, \% & & & \\
CP & 25.8 & 20.3 & 13.9 \\
Fat & 18.3 & 3.7 & 2.8 \\
ADF & - & 7.9 & 37.4 \\
NDF & - & 14.6 & 61.6 \\
Sugar & - & 7.7 & 2.1 \\
Starch & - & 39.6 & 1.8 \\
Ash & 6.6 & 6.9 & 9.3 \\
Calcium & 0.66 & 0.93 & 0.41 \\
Phosphorus & 0.63 & 0.63 & 0.36 \\
Magnesium & 0.09 & 0.29 & 0.16 \\
Potassium & 1.44 & 0.99 & 2.83
\end{tabular}

${ }^{1}$ Manufactured with whey, whey protein concentrate, and animal fat.

${ }^{2}$ Manufactured with $37 \%$ whole corn, $35 \%$ protein-mineral pellet, $25 \%$ whole oats, and $3 \%$ liquid molasses. 
(colormetric method; Dubois et al., 1956). Nutrient analysis of the refused feed for each wk and pen was similar to composition of feed offered.

In phase 1, data were first grouped by week, except hip width and BCS change, which were grouped by 14-d periods. The data were analyzed as a completely randomized block design with repeated measures when applicable by Proc Mixed in SAS (version 8, SAS Institute Inc., Cary, $\mathrm{NC}$ ). The 48 calf groups received $35 \mathrm{~d}$ apart were the blocks. An auto-regressive type 1 covariance matrix was employed as determined using Akaike's information criteria. Abnormal fecal score days and medical days were summed over phase 1 and analyzed using Kruskal-Wallis test with Proc NPAR1WAY in SAS. Calf (1 calf per pen) was the experimental unit. In phase 2, intake and growth data were analyzed as a completely randomized block design with repeated measures when applicable (grouped by two 28-d periods for body measurements) by Proc Mixed in SAS. An auto-regressive type 1 covariance matrix was employed as determined using Akaike's information criteria. Pen was the experimental unit. Significance was determined at $P \leq 0.05$. Trends were considered at $P \leq 0.09$.

\section{RESULTS AND DISCUSSION}

Initial measurements on $\mathrm{d} 0$ of phase 1 did not differ (Table 2). No preweaning measurements differed. Postweaning starter intake ( 2.13 vs. $2.00 \mathrm{~kg} / \mathrm{d})$ and ADG $(0.94$ vs. $0.86 \mathrm{~kg} / \mathrm{d})$ were greater $(P<0.01)$ for TUL than CON. Overall ADG (0.69 vs. $0.66 \mathrm{~kg} / \mathrm{d})$ and final BW (78.0 vs. $77.6 \mathrm{~kg})$ were greater $(P<0.05)$ for TUL than CON. Medical treatment d did not differ. For CON, there were 5 calves treated for navel infections and 2 calves treated for BRD (symptoms were nasal discharges with fever and lethargy). For TUL, there were 6 calves treated for navel infections and 1 calf treated for BRD (a symptom of nasal discharge). All navel infections were identified and treatments began on d 0 . No abnormal breathing sounds were detected by auscultation on d 28, 42, or 56. Abnormal fecal score also did not differ. All fecal samples from calves with abnormal feces tested positive for Cryptosporidium and Rotavirus. During phase 2, DMI did not differ; however, DMI as a percentage of BW (2.97 vs. $2.81 \%$ of BW) was greater $(P<0.01)$ for CON than TUL (Table 3$)$. Calf ADG (1.21 vs. $1.08 \mathrm{~kg} /$ d), final BW (137.8 vs. $145.8 \mathrm{~kg}$ ), feed efficiency ( 0.369 vs. $0.331 \mathrm{G}: \mathrm{F}$ ), and hip width change $(5.5$ vs. $4.8 \mathrm{~cm})$ were greater $(P<0.03)$ for TUL than CON. Over the $112 \mathrm{~d}$ of both phases, the difference in BW was $9.0 \mathrm{~kg}(9 \%)$ of BW (106.4 kg for TUL and $97.4 \mathrm{~kg}$ for $\mathrm{CON})$ and $0.8 \mathrm{~cm}(8 \%)$ for hip width change $(10 \mathrm{~cm}$ for TUL and $9.2 \mathrm{~cm}$ for $\mathrm{CON}$ ).

Stressors are a trigger of disease in calves through their effect on cortisol and various cytokines, and stressors occur frequently in the first 2 mo of life (Hulbert and Moisá, 2016). Significant stressors in the life of a calf include castration, dehorning, weaning, commingling, and vaccina- tion (Hulbert and Moisá, 2016), and these stressors frequently occur after 3 wk of age when respiratory disease is most prevalent. Stressors combined with the presence of viruses allow bacterial colonization of the lungs and are a typical reason for the onset of respiratory disease (Yates, 1982). A common outcome of BRD in calves is decreased weight gain and wither height. Indeed, Stanton et al. (2010) showed that calves that developed BRD before 8 wk of age experienced decreased weight gain and wither height. Detection can be difficult but critical to treatment, and recovery from the disease can affect performance later in life. This was demonstrated in a study with 795 Holstein calves where identification and treatment of disease before 2 mo of age improved first- and subsequent-lactation milk production (Heinrichs and Heinrichs, 2011).

Calves in the current trial faced many stressors including a 3.5-h transport from their birth farm to the research facility, several vaccinations, castrating, dehorning, weaning, and commingling. Over the $112 \mathrm{~d}$ on trial, the calves appeared healthy based on the few illnesses identified. Navel infections on d 0 were the predominate illness identified. These infections were evenly distributed between CON and TUL calves. All but one calf with a navel infection did not have iodine-stained hair around their navels as calves did without navel infections; thus, source-farm personnel likely did not properly dip their navels at birth.

In the studies by Stanton et al. (2010, 2012, 2013), calves previously treated for respiratory disease had decreased growth and increased mortality rates later in life than calves not treated for respiratory disease. Stanton et al. (2013) compared metaphylactic treatment with TUL at approximately $3 \mathrm{~d}$ of age with no treatment and reported that calves treated with TUL had a lower incidence of diarrhea, otitis media, and an approximately $4 \%$ increase in BW gain $(0.02 \mathrm{~kg} / \mathrm{d})$ between $3 \mathrm{~d}$ and $2 \mathrm{mo}$ of age.

Stanton et al. $(2010,2012)$ reported that ADG and height gain was not altered by TUL versus oxytetracycline treatment at approximately 2 mo of age in calves that had a respiratory disease before approximately $3.2 \mathrm{mo}$ of age. However, in calves without disease, ADG $(0.13 \mathrm{~kg} / \mathrm{d})$ and withers height gain $(0.04 \mathrm{~cm} / \mathrm{d})$ were increased by TUL versus oxytetracycline metaphylactic treatment. Our improvement in both BW gain and hip width gain between TUL and CON was consistent with the report by Stanton et al. $(2010,2012)$.

Stanton et al. (2012) followed the same group of calves from their 2010 study to 13 mo of age and found that calves never treated for respiratory disease maintained heavier BW at 3,6,9, and 13 mo of age if treated metaphylactically with TUL versus oxytetracycline. However, the effect of TUL on withers height growth after approximately 3 mo of age was uncertain, but wither heights of all calves (healthy and sick) were greater at 9 mo with TUL versus oxytetracycline treatment.

Stanton et al. $(2012,2013)$ attributed improvements in growth to reduction of disease in calves. In our studies, the 
identification of disease was low. We speculate that that there was some level of BRD that was not identified and that TUL may have reduced subclinical disease to allow for more BW and structural growth.

In our trial, healthy calves gained approximately $8 \%$ more BW and hip width from $3 \mathrm{~d}$ to $4 \mathrm{mo}$ of age. In the trials by Stanton et al. (2010, 2012, 2013), healthy calves experienced improved BW and structural growth in the first 3 mo of age when metaphylactically administered TUL. Growth experienced in the first 3 mo of life appeared to be maintained to approximately 12 mo of age in the study by Stanton et al. (2012). Because our calves appeared healthy and the medical treatments of $\mathrm{CON}$ were low, medical treatments for disease were not affected

Table 2. Performance of calves (48 per treatment) from 0 to $56 \mathrm{~d}$ (phase 1 ) that had not been treated (CON) or were treated (TUL) with Draxxin ${ }^{1}(2.5 \mathrm{mg}$ of tulathromycin/kg of BW) near birth and weaning (43 d apart)

\begin{tabular}{lllll} 
Item & CON & TUL & SEM & $P$-value \\
\hline Initial serum protein, mg/dL & 5.5 & 5.6 & 0.14 & 0.08 \\
Initial BW, kg & 40.6 & 39.3 & 1.08 & 0.86 \\
Final BW, kg & 77.6 & 78.0 & 0.14 & 0.05 \\
Initial hip width, cm & 17.1 & 16.8 & 0.28 & 0.70 \\
Final hip width, cm & 21.6 & 21.4 & 0.20 & 0.31 \\
Initial BCS & 2.1 & 2.1 & 0.04 & 0.51 \\
Final BCS & 2.4 & 2.4 & 0.03 & 0.19 \\
Before weaning (0 to 42 d) & & & & \\
Starter intake, kg/d & 0.44 & 0.49 & 0.042 & 0.32 \\
ADG, kg/d & 0.60 & 0.61 & 0.023 & 0.38 \\
Feed efficiency ${ }^{3}$ & 0.541 & 0.528 & 0.0201 & 0.98 \\
Hip width change, cm & 2.8 & 3.1 & 0.21 & 0.26 \\
BCS change & 0.2 & 0.2 & 0.04 & 0.79 \\
Fecal score & 2.1 & 2.1 & 0.02 & 0.87 \\
Abnormal fecal days, ${ }^{5}$ no. & 0.1 & 0.1 & 0.07 & 0.70 \\
Medical days, no. & 0.8 & 0.9 & 0.23 & 0.20 \\
After weaning (43 to 56 d) & & & & \\
Starter intake, kg/d & 2.00 & 2.13 & 0.051 & 0.01 \\
ADG, kg/d & 0.86 & 0.94 & 0.014 & 0.01 \\
Feed efficiency & 0.435 & 0.440 & 0.0355 & 0.42 \\
Hip width change, cm & 1.7 & 1.5 & 0.16 & 0.78 \\
BCS change & 0.1 & 0.1 & 0.03 & 0.76 \\
Fecal score & 2.0 & 2.0 & 0.03 & 0.89 \\
Abnormal fecal days, no. & 0.0 & 0.0 & - & - \\
Medical days, no. & 0.0 & 0.1 & 0.13 & 0.72 \\
Overall & & & & \\
Starter intake, kg/d & 0.83 & 0.90 & 0.039 & 0.08 \\
ADG, kg/d & 0.66 & 0.69 & 0.009 & 0.02 \\
Feed efficiency & 0.515 & 0.506 & 0.0174 & 0.70 \\
Hip width change, cm & 4.4 & 4.5 & 0.23 & 0.22 \\
BCS change & 0.3 & 0.3 & 0.05 & 0.63 \\
Fecal score & 2.0 & 2.0 & 0.01 & 0.94 \\
Abnormal fecal days, no. & 0.1 & 0.05 & 0.08 & 0.11 \\
Medical days, no. & 0.8 & 1.0 & 0.27 & 0.20 \\
\hline & & & &
\end{tabular}

'Zoetis (Florham Park, NJ).

${ }^{2} \mathrm{~A} 1$-to- 5 point system with 1 being thin and 5 being obese, modified from Wildman et al. (1982).

${ }^{3}$ Feed efficiency was calculated as BW gain divided by the sum of milk replacer and starter intake.

${ }^{4}$ Feces were scored daily using a 1 -to- 5 scale with 1 being normal and 5 being watery, modified from Kertz and Chester-Jones (2004).

${ }^{5}$ Days with fecal scores of 3 or greater. 
Table 3. Performance of calves (12 pens per treatment, 4 calves per pen) from 56 to $112 \mathrm{~d}$ (phase 2) that had not been treated (CON) or were treated (TUL) with Draxxin ${ }^{1}(2.5 \mathrm{mg}$ of tulathromycin/kg of BW) near birth and weaning (43 d apart)

\begin{tabular}{lrrrc} 
& CON & TUL & SEM & $P$-value \\
\hline Item & 77.6 & 78.0 & 1.74 & 0.26 \\
Initial BW, kg & 137.8 & 145.2 & 1.88 & 0.01 \\
Final BW, kg & 21.6 & 21.4 & 0.18 & 0.76 \\
Initial hip width, cm & 26.3 & 27.1 & 0.22 & 0.03 \\
Final hip width, cm & 2.4 & 2.4 & 0.04 & 0.22 \\
Initial BCS ${ }^{2}$ & 2.9 & 2.9 & 0.04 & 0.94 \\
Final BCS & 3.3 & 3.3 & 0.05 & 0.49 \\
DMl, kg/d & 2.97 & 2.81 & 0.026 & 0.01 \\
DMI, \% of BW & 1.08 & 1.21 & 0.013 & 0.01 \\
ADG, kg/d & 0.331 & 0.369 & 0.0061 & 0.01 \\
Feed efficiency, ${ }^{3}$ G:F & 4.8 & 5.5 & 0.15 & 0.01 \\
Hip width change, cm & 0.5 & 0.5 & 0.04 & 0.23 \\
BCS change & & & &
\end{tabular}

'Zoetis (Florham Park, NJ).

${ }^{2}$ A 1 -to- 5 point system with 1 being thin and 5 being obese, modified from Wildman et al. (1982).

${ }^{3}$ Feed efficiency was calculated as BW gain divided by DMI.

by TUL. Under the conditions of our study with healthy calves, TUL improved calf BW and hip width gain from 3 d to 4 mo of age by approximately $8 \%$.

\section{IMPLICATIONS}

Metaphylactic treatment of dairy calves with Draxxin (2.5 mg of tulathromycin $/ \mathrm{kg}$ of BW) near birth (approximately $3 \mathrm{~d}$ of age) and $43 \mathrm{~d}$ later at weaning increased BW and hip width gain by approximately $8 \%$ from 0 to 4 mo of age. In general, calves in the trial were healthy, and few calves were treated for respiratory and enteric disease.

\section{ACKNOWLEDGMENTS}

This research was fully funded by Provimi (Brookville, $\mathrm{OH})$.

\section{LITERATURE CITED}

AOAC International. 2000. Official Methods of Analysis. Vol. I, 17th ed. AOAC Int., Arlington, VA.

Dubois, M., K. A. Gilles, J. K. Hamilton, P. A. Rebers, and F. Smith. 1956. Colorimetric method for determination of sugars and related substances. Anal. Chem. 28:350-356.

FASS. 2010. Guide for the Care and Use of Agricultural Animals in Agricultural Research and Teaching. 3rd ed. FASS Inc., Champaign, IL.

Hall, M. B. 2009. Analysis of starch, including maltooligosaccharides, in animal feeds: A comparison of methods and a method recommended for AOAC collaborative study. J. AOAC Int. 92:42-49.
Heinrichs, A. J., and B. S. Heinrichs. 2011. A prospective study of calf factors affecting first-lactation and lifetime milk production and age of cows when removed from the herd. J. Dairy Sci. 94:336-341.

Hulbert, L. E., and S. J. Moisá. 2016. Stress, immunity, and the management of calves. J. Dairy Sci. 99:3199-3216.

Kertz, A. F., and H. Chester-Jones. 2004. Invited Review: Guidelines for measuring and reporting calf and heifer experimental data. J. Dairy Sci. 87:3577-3580.

Robertson, J. B., and P. J. Van Soest. 1981. The Detergent System of Analysis and Its Application to Human Foods. Cornell Univ., Ithaca, NY.

Stanton, A. L., D. F. Kelton, S. J. LeBlanc, S. T. Millman, J. Wormuth, R. T. Dingwell, and K. E. Leslie. 2010. The effect of treatment with long-acting antibiotic at postweaning movement on respiratory disease and on growth in commercial dairy calves. J. Dairy Sci. $93: 574-581$.

Stanton, A. L., D. F. Kelton, S. J. LeBlanc, J. Wormuth, L. K. Fox, and K. E. Leslie. 2012. The effect of respiratory disease and a preventative antibiotic treatment on growth, survival, age at first calving, and milk production of dairy heifers. J. Dairy Sci. 95:4950-4960.

Stanton, A. L., D. F. Kelton, S. J. LeBlanc, J. Wormuth, L. K. Fox, and K. E. Leslie. 2013. Effects of tulathromycin on incidence of various diseases and growth of young heifers. J. Am. Vet. Med. Assoc. $243: 267-276$.

Svensson, C., K. Lundborg, U. Emanuelson, and S. O. Olsson. 2003. Morbidity in Swedish dairy calves from birth to 90 days of age and individual calf-level risk factors for infectious diseases. Prev. Vet. Med. 58:179-197.

USDA-APHIS (Animal and Plant Health Inspection Service). 1999. Part III: Health management and biosecurity in U.S. feedlots. No. N336.1200. USDA-APHIS-VS-CEAH, Fort Collins, CO. Accessed Aug. 29, 2016. https://www.aphis.usda.gov/animal_health/nahms/ feedlot/downloads/feedlot99/Feedlot99_dr_PartIII.pdf. 
USDA-APHIS (Animal and Plant Health Inspection Service). 2009. Dairy 2007, Part IV: Reference of dairy cattle health and management practices in the United States, 2007. USDA-APHIS-VS-CEAH, Fort Collins, CO. Accessed Aug. 29, 2016. http://www.aphis.usda. gov/animal_health/nahms/dairy/downloads/dairy07/Dairy07_dr_ PartIV.pdf.

Van Soest, P. J., J. B. Robertson, and B. A. Lewis. 1991. Methods for dietary fiber, neutral detergent fiber, non-starch polysaccharides in relation to animal nutrition. Symposium: carbohydrate methodology, metabolism and nutritional implications in dairy cattle. J. Dairy Sci. 74:3583-3597.

Weese, J. S. 2006. Prudent use of antimicrobials. Pages 437-448 in Antimicrobial Therapy in Veterinary Medicine. 4th ed. S. Giguère,
J. F. Prescott, J. D. Baggot, R. D. Walker, and P. M. Dowling, ed. Blackwell Publ., Ames IA.

Weese, J. S., S. Giguere, L. Guardabassi, P. S. Morley, M. Papich, D. R. Ricciuto, and J. E. Sykes. 2015. ACVIM consensus statement on therapeutic antimicrobial use in animals and antimicrobial resistance. J. Vet. Intern. Med. 29:487-498.

Wildman, E. E., G. M. Jones, P. E. Wagner, R. L. Bowman, H. F. Troutt Jr., and T. N. Lesch. 1982. A dairy cow body condition scoring system and its relationship to selected production characteristics. J. Dairy Sci. 65:495-501.

Yates, W. D. 1982. A review of infectious bovine rhinotracheitis, shipping fever pneumonia and viral-bacterial synergism in respiratory disease of cattle. Can. J. Comp. Med. 46:225-263. 